\title{
PENSATA
}

Artigo convidado

Versão original

DOI: http://dx.doi.org/10.1590/Soo34-759020210107

\section{PASSADO, PRESENTE E FUTURO DE HISTÓRIA (CRÍTICA) DAS ORGANIZAÇÕES NO BRASIL}

O objetivo deste artigo é construir uma narrativa acerca da trajetória da incorporação da história, da memória e do passado nas pesquisas de estudos organizacionais (EO) no Brasil e refletir sobre seus possíveis desdobramentos. Como toda pesquisa acerca do passado, assume-se que essa narrativa é uma versão possível (e espera-se que crível) que não inviabiliza outras. Pelo contrário. Sem a pretensão de apresentar-se como um manifesto e/ou cristalizar uma narrativa específica, busca-se a abertura para o diálogo e para a construção compartilhada de uma comunidade científica em torno do tema.

A relevância dessa construção reside no fato de que a trajetória de aproximação de duas áreas disciplinares tão diferentes como EO e História (Rowlinson, Hassard, \& Decker, 2014) também pode ser compreendida como a trajetória de formação de um campo de pesquisa no Brasil.

Deve-se ressaltar, no entanto, que o contexto institucional de aproximação e diluição de fronteiras entre as áreas não foi o mesmo de outros espaços acadêmicos fora do país (como norteamericanos e europeus). Não ocorreu, por exemplo, um crescimento no número de transferências de historiadores de empresas (e de negócios) dos departamentos de História das universidades para as escolas de Administração (Decker, 2013). Ao contrário, os pesquisadores responsáveis pela construção dessa ponte no Brasil foram (e são), salvo raras exceções, da própria área de gestão. Dessa forma, a História de Negócios (business history) não adquire muita relevância nos EO brasileiros, permanecendo forte apenas na área de estudos do pensamento econômico brasileiro dos cursos de Economia.

Portanto, desde os anos 2000 , são pesquisadores de diferentes matrizes teóricometodológicas da área de Gestão e de EO no Brasil que buscam defender e justificar a importância do estudo da História em suas pesquisas como uma forma de enriquecer a compreensão acerca dos fenômenos organizacionais no presente. Para articular essa trajetória, optou-se pela construção de um recorte e de um ordenamento temporal, estabelecendo, assim, origem e sentido. E, assumindo que qualquer periodização é uma construção política dos pesquisadores (Prost, 2012), escolhemos, arbitrariamente, os seguintes marcos históricos como norte para a narrativa: (1) os anos 2000; (2) os anos 2010; e (3) os anos 2020.

\section{Anos 2000: Por mais história e memória nas pesquisas nacionais}

A trajetória da pesquisa histórica em Gestão e EO iniciou-se com uma atuação mais pontual, tanto na área de pesquisa quanto na formação e orientação discente, de pesquisadores interessados na história da Administração brasileira. 0 foco era identificar e analisar o que o Brasil tinha de contextual 
e específico (para além dos modelos teóricos universais e das grandes narrativas que encapsulavam particularidades) por meio da análise histórica de suas organizações e práticas sociais.

Um dos marcos iniciais desse movimento é a tese de Tania Fischer (1984), “O Ensino de Administração Pública no Brasil, os ideais de desenvolvimento e as dimensões da racionalidade". Nesse trabalho, a autora investigou, por meio de documentos, o ensino de Administração pública no Brasil, sugerindo que "a criação e o desenvolvimento da EBAP foram uma decorrência da ideologia desenvolvimentista vigente no país desde as décadas de 40/50" (Fischer, 1984, p. 12). Posteriormente, outros pesquisadores também contribuíram para esse movimento, como é o caso de Carlos Osmar Bertero (FGV EAESP), com pesquisas sobre ensino e pesquisa em Administração no Brasil; Paulo Emílio Matos Martins (UFF, FGV EBAPE), com pesquisas sobre Administração, História e pensamento social brasileiro; e Alexandre de Pádua Carrieri (UFMG), com pesquisas sobre histórias, memória e cotidiano.

Entretanto, somente a partir dos anos 2000, pode-se identificar, de modo mais recorrente, dissertações de mestrado e teses de doutorado sendo defendidas e publicadas em fóruns de discussão da área de Gestão e EO. Esse é o caso, apenas para citar alguns exemplos, das teses de Isabela Baleeiro Curado (2001), Ariston Azevedo (2006), Fernando Coelho (2006), Fábio Vizeu (2008) e Claudiani Waiandt (2009). Junto com a emergência dos trabalhos desses pesquisadores, e em sintonia com a virada histórica em EO (Booth \& Rowlinson, 2006; Clark \& Rowlinson, 2004), começaram também a surgir reinvindicações por mais história, ressaltando a importância da perspectiva histórica para compreender as organizações no tempo e no espaço e a relevância da pesquisa histórica como forma de acesso ao conhecimento (Costa, Barros, \& Martins, 2010; Vizeu, 2010).

Assim, os interesses dos pesquisadores alinhados com a temática da história residiam, nesse momento, essencialmente: (a) na reflexão sobre a práxis social do pesquisador; (b) na consideração acerca do potencial enriquecimento das pesquisas ao serem considerados novos olhares sobre objetos, problemas e abordagens de pesquisa (Costa et al., 2010); e (c) na urgência de se deslocar o foco de análise do exógeno para o local, resgatando os aspectos históricos e interculturais em oposição à reprodução ideológica dominante, que tende a excluir o passado ou o contexto das teorias e práticas organizacionais (Vizeu, 2008, 2010).

Posteriormente, a demanda foi ampliada não somente para contemplar a inclusão de mais história nas pesquisas mas também para outras formas de representação do passado, como a memória, a memória coletiva e as perspectivas biográficas relacionadas com fontes orais e narrativas memorialísticas (biografias, autobiografias, história oral e histórias de vida).

No caso mais específico da memória, pode-se identificar que grande parte dos estudos internacionais de memória (e dos espaços organizacionais de memória) na área de Gestão foca seu uso mais instrumental, sendo a memória organizacional compreendida como um repositório de informações sobre o passado passível de ser acessado e usado pelos gestores de empresas no processo de tomada de decisão (Walsh \& Ungson, 1991). Ou seja, acessar o passado organizacional por meio de um banco de informações que acumula, sistematiza e ordena o conhecimento acerca do que já aconteceu passa a ser compreendido como uma preciosa fonte de aprendizado organizacional e mesmo de vantagem competitiva (Holan \& Phillips, 2004). No caso das pesquisas brasileiras em EO, esse não foi bem o caso. Mais alinhados com a proposta de Rowlinson, Booth, Delahaye e Pocter (2010), os estudos de memória, de memória social e dos espaços organizacionais de memória, por aqui, acabam por priorizar as fontes orais e a ideia de que a ascensão da história oral e dos métodos biográficos (em especial as histórias de vida) é capaz de contribuir para o avanço do conhecimento sobre o passado (Carrieri \& Lopes, 2012; Lopes \& Carrieri, 2010).

No entanto, apesar de significativas, as tentativas nacionais de aproximações entre as áreas ainda eram incipientes, uma vez que, apesar dos esforços e das articulações, ainda não existiam “[...] associações, centros de pesquisa, periódicos especializados ou espaço exclusivo para discussão em congressos nacionais acerca da perspectiva histórica em Administração" (Costa et al., 2010, p. 289)". Esse quadro, nos anos seguintes, altera-se, configurando (no nosso entendimento) um novo marco na trajetória do movimento em questão. Para além das demandas por mais história e memória nas pesquisas, a partir dos anos 2010, inicia-se um movimento mais sistematizado e formal de atribuir relevância à pesquisa histórica como procedimento teórico-metodológico. Surgem, em periódicos e eventos da área, publicações, painéis e oficinas de trabalho sobre como fazer pesquisa histórica em EO.

\section{Anos 2010: Por mais conhecimento acerca dos procedimentos teórico-metodológicos da pesquisa histórica}

Pode-se argumentar, a partir de alguns indícios, que, a partir dos anos 2010, no Brasil, a temática adquire mais legitimidade e representatividade na área de EO. Primeiro, como desdobramento 
do período anterior, o número de teses e dissertações que incorporam a temática continua a crescer, como é o caso, por exemplo, de Lima (2009), Barros (2013), Lopes (2019), Joaquim (2014), Silva, MAF (2018), Silva, E (2019) e Correia (2020), da UFMG; Carneiro (2015, 2019), da EAESP/FGV; Wanderley (2015), da EBAPE/FGV; Calgaro (2016), Morgado (2016) e Biscaia (2018), da UP; Caminha (2014), da UFRGS; Souza (2016) e Silva (2017), da UFBA; Chaym (2017), Bezerra (2019) e Lopes (2019), da UECE; Pio (2018) e Boschi (2018), da Unigranrio; Silva, MAC (2018), Quelha-de-Sá (2018), Fucs (2019) e Santos (2019), da PUC-Rio.

Para além desse movimento dentro dos Programas de Pós-Graduação, outro indício foi a criação, em 2011, no âmbito da divisão de EO da Associação Nacional de Pós-Graduação e Pesquisa em Administração (ANPAD), do tema de interesse “História e memória em organizações”. O Coordenador da Divisão de EO na época era Alexandre de Pádua Carrieri (UFMG), e o novo tema foi liderado por Monica de Aguiar McAllister (UFBA). O descritor do tema, formalizado pela primeira vez no maior congresso de Administração brasileiro, é um bom indicativo dos interesses e do percurso dos pesquisadores no período:

Estudos organizacionais e também históricos, sob qualquer orientação epistemológica, ontológica, teórica e metodológica de história; incluindo análises organizacionais desenvolvidas a partir de abordagens históricas, com a construção de quadros teóricos e conceituais históricos, e que utilizam métodos históricos. Construções históricas da realidade organizacional brasileira e que aproximam o conhecimento organizacional dessa realidade. Pesquisas históricas que contribuem para a inovação da produção de conhecimento sobre organização. (ANPAD, 2020)

A partir desse momento, o tema teve outros líderes e, até os dias de hoje, permanece ativo não só na esfera dos eventos da ANPAD mas também em eventos de outras associações, como nas últimas três edições do Congresso da Sociedade Brasileira de Estudos Organizacionais (CBEO).

Um terceiro indício que nos permite pensar em um processo de formalização da temática em EO é o início da criação de uma linha historiográfica de História do Management no Brasil. Com o foco nessa perspectiva de análise, um conjunto de pesquisadores investiga tanto a história da Administração no Brasil (Alcadipani \& Bertero, 2018) quanto o papel de periódicos na construção do campo (Tonelli, 2017, 2018), e a história do ensino de Administração no Brasil por meio da análise da história de organizações específicas, como: FGV/EAESP (Alcadipani \& Bertero, 2012, 2014), FGV/EAESP e FEA (Valle, Bertero, \& Alcadipani, 2013), FACE/UFMG (Barros, 2014), UFBA (Bertero, Barros, \& Alcadipani, 2018), UFRGS (Barros, Alcadipani, \& Bertero, 2018), Escolas de Comércio e Ensino Superior (Barros, 2013, 2017; Barros \& Carrieri, 2013), ISEB e CEPAL (Wanderley, 2015, 2016) e IDORT (Vizeu, 2018).

Como último ponto, em relação aos procedimentos teórico-metodológicos das pesquisas que fazem uso da história e da memória (Lipartito, 2014; Yates, 2014), estes ainda não alcançaram - também no Brasil - todo o seu potencial de diálogo interdisciplinar (Wadhwani, Suddaby, Mordhorst, \& Popp, 2018). Pode-se afirmar que o método histórico é fácil de circunscrever, o que não quer dizer que seja de fácil implementação. Entretanto, como evidência dessa preocupação e de modo a tentar superar a situação atual, foram criadas disciplinas específicas nos cursos de pós-graduação em Administração sobre pesquisa histórica em EO, como é o caso da disciplina "História, Memória e Organizações" ministrada na UNIGRANRIO e na PUC-Rio; "Pesquisa Histórica em Administração” ministrada na PUC-Rio; e “Organizações, História e Linguagem" ministrada na Positivo. Ao mesmo tempo, cresce o número de oficinas de trabalho oferecidas no âmbito dos eventos nacionais já citados. 0 foco das disciplinas e oficinas é amplo, abrangendo desde como trabalhar com documentos históricos em arquivos físicos e digitais - importância já ressaltada por Barros (2016) e Coraiola (2012) - até como recolher e manusear fontes orais em pesquisas de história oral e histórias de vida (Barros \& Lopes, 2014).

Como ilustração (e reforço) desse argumento, o tema de interesse da temática em foco para o ENANPAD 2020 expressa em seu descritor, de maneira bastante clara, a importância atribuída aos procedimentos metodológicos da pesquisa histórica:

[...] são bem-vindos estudos que: Analisem como fontes e arquivos históricos contribuem para entender os fenômenos organizacionais e sua articulação com o social e o político; Estimulem debates sobre como a pesquisa histórica em administração e estudos organizacionais permite um engajamento com o passado que vá além do superficial ou do meramente descritivo; Discutam como as organizações instrumentalizam estrategicamente seu passado criando e gerindo seus acervos e arquivos documentais, construindo significados a partir de disputas entre memó rias oficiais e memórias silenciadas; Sejam baseados em fontes diversas tais como arquivos 
públicos, arquivos privados e/ou empresariais, arquivos da Comissão Nacional da Verdade; jornais de época; filmes; documentários e fontes baseadas em história oral, de vida e/ou temática; Resgatem as relações entre políticas públicas de Educação, organizações de educação e disciplinas da Administração. Nesse sentido, também são considerados nessa linha temática, textos que versem sobre o método biográfico em suas diversas abordagens históricas e psicossociais [...] (ANPAD, 2020b).

\section{Anos 2020: Em busca de um posicionamento crítico e reflexivo acerca do passado e suas formas de representação, rumo à internacionalização}

De modo a refletir sobre possíveis desdobramentos da trajetória histórica da incorporação da história, da memória e do passado nas pesquisas de EO no Brasil, um bom começo pode ser a publicação de Wanderley e Barros (2019). Os autores, sem pretensões de prever o futuro, nos oferecem algumas pistas acerca do que representa o desafio a ser enfrentado na próxima década: como conseguir, ao mesmo tempo, exercer uma opção por autores/teorias, conceitos e temas nacionais e manter o diálogo e a relevância com o público internacional?

Esse desafio, longe de ser uma novidade na área de EO (ver, por exemplo, Caldas \& Alcadipani, 2006), apresenta-se agora com toda a sua força também para esse campo de pesquisa. Se, por um lado, a consolidação da virada histórica proposta pelo mundo anglo-saxão proporcionou a legitimação do subcampo historical organization studies (Maclean, Harvey, Clegg, \& Stewart, 2016), levando a maiores possibilidades de publicação no exterior, por outro lado, a presença de autores e temas de outras geografias continua limitada (Wanderley \& Barros, 2019). A recente proposta de um subcampo ainda mais específico, critical organizational history (Durepos, Shaffner, \& Taylor, 2019), abre novas possibilidades, pois apresenta uma demanda por visões mais críticas e reflexivas acerca da virada histórica. Como está claro na chamada deste fórum, existe a necessidade de "explorar as implicações da virada histórica nos estudos de gestão e organizações com base em múltiplos aportes teóricos, epistemológicos, culturais e localizações geográficas" (Barros, Coraiola, Maclean, \& Foster, 2019, p. 1).

Ressaltamos aqui a necessidade da inclusão de outras geografias para além do mundo anglo-saxão na virada histórica (Wanderley \& Barros, 2019). Foram os próprios autores críticos do mundo anglo-saxão que alertaram para o fato de que, para que um diálogo entre pesquisadores para além desse mundo possa ocorrer, provavelmente temos que recorrer a autores como Marx, Foucault, Lacan e Gramsci (Mir \& Mir, 2012). Certamente, autores como Foucault e Gramsci abrem portas no exterior para publicações em história crítica das organizações. Contudo, devemos estar alertas para não nos tornarmos "pensadores críticos orgulhosos (ou avançados)", sem nos darmos conta de que estamos sendo eurocêntricos (Dussel \& Ibarra-Colado, 2006, p. 491).

Assim, nosso desafio pode ser traduzido pelo aforismo de Oswald de Andrade (1928), que devora antropofagicamente o dilema hamletiano: "Tupi, or not tupi that is the question". Em outras palavras, seguiremos o caminho seguro de aderirmos acriticamente às propostas (críticas) da virada histórica ou enfrentaremos o desafio de inscrevermos nossas diversas origens tupi - autores/teorias, conceitos e temas - na casa (internacional) do conhecimento?

Não existem caminhos fáceis a propor, mas estamos seguros de que não buscar nossas próprias representações do passado (histórias, memórias e ficções), autores, teorias e conceitos significaria perder relevância e, portanto, não se configura como uma opção plausível. Além disso, vários pesquisadores brasileiros têm enfrentado esse desafio e podem nos indicar possíveis caminhos a seguir. Por exemplo, Cooke e Alcadipani (2015) investigaram o financiamento da Fundação Ford para a EAESP/FGV para ilustrar uma possível história global do ensino de Administração. Alcadipani (2017), com base em uma abordagem pós-colonial - já consolidada no mundo anglo-saxão -, resgatou o conceito de redução sociológica de Guerreiro Ramos para sua investigação sobre a circulação do conhecimento em Administração na periferia. Barros e Wanderley (2019) lançaram mão do conceito de populismo de Francisco Weffort para investigar os fenômenos trumpism e Brexit. Esses dois últimos trabalhos mostram o potencial do pensamento social brasileiro na compreensão de fenômenos atuais. Quelha-de-Sá e Costa (2019) investigaram a história da construção do Memorial da Resistência de São Paulo com base no modelo teórico-metodológico ANTihistory - que tem origem no Canadá (Durepos \& Mills, 2012) - desvelando narrativas silenciadas e colocadas à margem pela história oficial da ditadura militar brasileira. Wanderley e Barros (2020) optaram pela abordagem teórico-metodológica conhecida como Burke's Pentad - do teórico da literatura estadunidense Kenneth Burke - para investigar como a Aliança para o Progresso influenciou o ensino de Administração para o desenvolvimento no Brasil. Barros e Taylor (2020) utilizaram os aportes teóricos de Gramsci para investigar a atuação no Brasil, nos anos 1960, do Instituto de Pesquisas e Estudos Sociais (IPES) e, assim, discutir como think tanks tornaram-se chaves no momento atual para a aceitação de ideologias pró-corporativas pela sociedade civil. 
Portanto, o que nos parece aqui se delinear é a articulação de um autor/teoria, conceito (Alcadipani, 2017; Barros \& Wanderley, 2019) ou tema nacional (Barros \& Taylor, 2020; Cooke \& Alcadipani, 2015; Quelha-de-Sá \& Costa, 2019; Wanderley \& Barros, 2020) com uma abordagem teórica ou metodológica internacional (Alcadipani, 2017; Barros \& Taylor, 2020; Quelhade-Sá \& Costa, 2019; Wanderley \& Barros, 2020) para que nossas diversas origens tupi possam adentrar e sentar à mesa da casa do conhecimento (anglo-saxão) e dialogar.

A opção por esse tipo de articulação pode ser também uma forma de evitarmos cair na armadilha do paroquialismo e seguirmos contando nossas próprias estórias para nós mesmos. Todavia, devemos estar atentos para não perdermos rigor ao promovermos a "tradução" de nossos temas para uma plateia internacional. Independentemente da articulação implementada, entendemos que a reflexividade como atitude metódica - como Guerreiro Ramos (1958) sugeriu para a redução sociológica - deve ser companheira em cada etapa da pesquisa histórica: na seleção do problema e das fontes, na elaboração da abordagem teórica, na construção do arcabouço metodológico e na construção da narrativa, que será sempre delineada pela "arte e artesanato" do pesquisador.

Sobretudo, entendemos que é necessário, para a formação de um campo de história crítica das organizações no Brasil, que nos apropriemos do conceito de perspectivismo ameríndio de Viveiros de Castro (2018). Dessa maneira, poderemos promover uma inversão da lógica promovida pelo mundo anglo-saxão na construção do conhecimento. Parafraseando Viveiros de Castro (2018), não se trata de usar autores (ocidentais) que nos são amplamente familiares - tais como Foucault e Gramsci - para investigar nossas estórias "exóticas”, mas sim de "ler os filósofos à luz do pensamento selvagem, e não o contrário: trata-se de atualizar os incontáveis devires-outrem que existem como virtualidades de nosso pensar" (p. 90). Portanto, devemos iniciar por nossos autores/teorias, conceitos e temas para articular com os similares internacionais. Ademais, Guerreiro Ramos (1958) já havia sugerido que, “à luz da redução sociológica, toda produção científica estrangeira é, em princípio, subsidiária” (p. 83).

Baseados nessas premissas, gostaríamos aqui de ampliar a agenda (internacionalizada) de pesquisa - absolutamente não exaustiva, mas sim um convite a sua extensão - para um subcampo de história crítica das organizações no Brasil em articulação com potenciais similares internacionais, tais como:

- $\quad$ articulação de autores e teorias. Autores do pensamento social brasileiro (já citados, mais ainda não explorados em todo o seu potencial, ver: Martins, Gurgel, Lima, Darbilly, Justen \&Santos 2013) tais como Darcy Ribeiro,
Milton Santos e Paulo Freire, articulados com os estudos decoloniais. Autores e teorias do Instituto Superior de Estudos Brasileiros (ISEB, 1955-1964), tais como Roland Corbisier, Álvaro Vieira Pinto, Hélio Jaguaribe, Candido Mendes e Nelson Werneck Sodré (ver Wanderley, 2016), articulados com autores da Escola de Frankfurt.

- $\quad$ articulação de conceitos. 0 conceito de superexploração do trabalho de Rui Mauro Marini (2012) articulado com o conceito de necrocapitalismo de Bobby Banerjee (2008) para investigar, por exemplo, o processo de uberização do trabalhador. 0 conceito de redução sociológica de Guerreiro Ramos (1958) com o conceito de reflexividade sugerido por Alvesson e Sköldberg (2000). O conceito de perspectivismo ameríndio (Castro, 2018) com os conceitos de border thinking (Mignolo \& Tlostanova, 2006) dos estudos decoloniais e third spaces (Bhabha, 1994) da abordagem pós-colonial.

- $\quad$ articulação de temas de pesquisa. A historiografia brasileira sobre o apoio e a participação das empresas em práticas de violação dos direitos humanos dos trabalhadores na ditadura militar brasileira (ver Costa \& Silva, 2017, 2018) articulado com a cumplicidade de corporações com regimes totalitários durante a 2- Guerra Mundial (ver Schrempf-Stirling, Palazzo, \& Phillips, 2016; Stokes \& Gabriel, 2010). Os impactos no Brasil do modelo de monocultura de exportação baseado na escravidão (ver Taunay, 2001) no surgimento do management, articulados com o modelo similar nos EUA conforme investigado, por exemplo, por Bill Cook (2003). Essa última sugestão pode nos ajudar a compreender as relações de trabalho que ainda hoje permeiam as organizações no Brasil. E os estudos de história, memória e processos narrativos organizacionais em espaços de memória de liberdade e resistência no Brasil (Quelha-de-Sá \& Costa, 2019) articulados com pesquisas sobre history-telling (Foster, Coraiola, Suddaby, Kroezen, \& Chandler, 2017), responsabilidade histórica corporativa (Coraiola \& Derry, 2019) e rethorical history (Suddaby, Foster, \& Trank, 2016).

Mormente, esse é o objetivo de uma agenda inicial em história crítica das organizações (e não só no Brasil): (re)visitar o passado para desnaturalizar e confrontar o presente e, assim, imaginar 
futuros possíveis. O maior desafio, com certeza, é o mesmo que a área de EO vem enfrentando em outros subcampos: a construção de abordagens teórico-metodológicas para além do estrangeiro. Dito de outra maneira, nossa agenda seria, como poetizou Manuel Bandeira sobre o projeto de Lúcio Costa para a construção de Brasília (capital federal), "um avião em rota para a impossível Utopia, [mas cujo projeto] logo dá à iniciativa, que parecia uma aventura, um ar plausível”. Vinte anos atrás, perseguir uma agenda em história crítica das organizações poderia parecer "uma aventura”, porém hoje temos o "ar plausível” da institucionalização no Brasil e no exterior de um profícuo campo de pesquisa. Isso nos proporciona maior visibilidade, todavia aumenta nossa responsabilidade com o rigor e a relevância de nossas pesquisas. Sigamos juntos.

\section{REFERÊNCIAS}

Alcadipani, R. (2017). Reclaiming sociological reduction: Analyzing the circulation of management education in the periphery. Management Learning, 48(5), 535-551. doi: 10.1177/1350507617710321

Alcadipani, R., \& Bertero, C. (2012). Guerra fria e ensino do management no Brasil: O caso da FGV-EAESP. RAE-Revista de Administração de Empresas, 52(3), 284-299. doi: 10.1590/So034-75902012000300002

Alcadipani, R., \& Bertero, C. (2014). Uma escola americana no ultramar? Uma historiografia da EAESP. RAE-Revista de Administração de Empresas, 54(2), 154-169. doi: 10.1590/So034-759020140204

Alcadipani, R., \& Bertero, C. (2018). Os EUA, a exportação e a expansão do ensino de management no Brasil nas décadas de 1950 e 1960 Cadernos EBAPE.BR (FGV), 16(1), 50-63. doi: 10.1590/1679-395131512

Alvesson, M., \& Sköldberg, K. (2000). Reflexive methodology: New vistas for qualitative research. London, UK: Sage.

Andrade, O. (1928). Manifesto antropófago. Revista de Antropofagia, (1).

Associação Nacional de Pós-Graduação e Pesquisa em Administração - ANPAD. (2020). Descritor do Tema 10 da Divisão de Estudos Organizacionais do EnANPAD 2011. Retrieved from http://www.anpad.org. $\mathrm{br} /$ eventos.php?cod_evento $=1 \&$ cod_evento_edicao $=58 \&$ cod_edicao_subsecao $=676$

Associação Nacional de Pós-Graduação e Pesquisa em Administração - ANPAD. (2020b). Descritor do Tema 7 da Divisão de Estudos Organizacionais do EnANPAD 2020. Retrieved from http://www.anpad.org. $\mathrm{br} /$ eventos.php?cod_evento $=1 \&$ cod_evento_edicao $=106 \&$ cod_edicao_subsecao $=1692$

Azevedo, A. (2006). A sociologia antropocêntrica de Alberto Guerreiro Ramos (Tese de doutorado, UFSC).

Banerjee, B. (2008). Necrocapitalism. Organization Studies, 29(12), 1541-1563. doi: 10.1177/0170840607096386

Barros, A. (2013). Uma narrativa sobre a história dos cursos de administração da FACE-UFMG: Às margens do mundo e à sombra da FGV? (Tese de doutorado, Cepead/Cad/Face/Universidade Federal de Minas Gerais).

Barros, A. (2014). Uma narrativa sobre os cursos superiores em administração da FACE/UFMG: Dos primeiros anos à sua unificação em 1968. Cadernos EBAPE.BR (FGV), 12(1), 7-25. doi: 10.1590/S167939512014000100003
Barros, A. (2016). Archives and the "archive": Dialogue and an agenda of research in organization studies. Organizações \& Sociedade, 23(79), 609-623. doi: 10.1590/1984-9230795

Barros, A. (2017). Antecedentes dos cursos superiores em administração brasileiros: As escolas de comércio e o curso superior em administração e finanças. Cadernos EBAPE.BR, 15(1), 88-100. doi: $10.1590 / 1679-395146748$

Barros, A., Alcadipani, R., \& Bertero, C. (2018). A criação do curso superior em administração na UFRGS em 1963: Uma análise histórica. RAE-Revista de Administração de Empresas, 58(1), 3-15. doi: 10.1590/ S0034-759020180102

Barros, A., \& Carrieri, A. (2013). Ensino superior em administração entre os anos 1940 e 1950: Uma discussão a partir dos acordos de cooperação Brasil-Estados Unidos. Cadernos EBAPE.BR, 11(2), 256273. doi: $10.1590 /$ S1679-39512013000200005

Barros, A., Coraiola, D., Maclean, M., \& Foster, W. (2019). History, memory, and the past in management and organization studies [Call for Papers]. Recuperado de https://rae.fgv.br/sites/rae.fgv.br/files/ arquivos/call_for_papers_2019_history_o.pdf

Barros, A., \& Taylor, S. (2020). Think tanks, business and civil society: The ethics of promoting pro-corporate ideologies. Journal of Business Ethics, 162(3), 505-517. doi: 10.1007/s10551-018-4007-y

Barros, A., \& Wanderley, S. (2019). Brazilian businessmen movements: Right-wing populism and the (dis) connection between policy and politics. Organization, 27(3) 394-404. doi: $10.1177 / 1350508419883378$

Barros, V., \& Lopes, F. (2014). Considerações sobre a pesquisa em história de vida. In E. M. de Souza (Org.). Metodologias e analíticas qualitativas em pesquisa organizacional: Uma abordagem teóricoconceitual. Vitória: EDUFES.

Bertero, C., Barros, A., \& Alcadipani, R. (2018). Missionários americanos na Bahia: O bacharelado em administração da Escola de Administração da UFBA. Cadernos EBAPE.BR (FGV), 17(1), 144155. doi: $10.1590 / 1679-395164890$

Bezerra, M. (2019). Para além de um evento de artes: A ANTi-history de uma organização artística (Dissertação de mestrado, Universidade Estadual do Ceará).

Bhabha, R. (1994). The location of culture. London, UK: Routledge.

Biscaia, P. (2018). A influência de abolicionistas e escravocratas brasileiros na atuação de uma organização bancária no século XIX (Dissertação de mestrado, Universidade Positivo).

Booth, C., \& Rowlinson, M. (2006). Management and organizational history: Prospects. Management \& Organizational History, 1(1), 5-30. doi: $10.1177 / 1744935906060627$

Boschi, M. (2018). A origem da educação executiva em marketing no Brasil: Uma perspectiva histórica (Tese de doutorado, Unigranrio).

Caldas, M., \& Alcadipani, R. (2006). Americanização e pós-colonialismo: A gênese da referência norte-americana na cultura e gestão no Brasil. In J. F. Chanlat, R. Fachin, \& T. Fischer (Eds.), Análise das organizações, perspectivas latinas: Olhar histórico e constatações atuais, (pp. 261. 294). Porto Alegre, RS: UFRGS.

Calgaro, R. (2016). A empresificação das cooperativas no Brasil: Um estudo histórico de uma cooperativa de crédito (Tese de doutorado, Universidade Positivo).

Caminha, D. (2014). Origens sociais, trajetórias e estratégias de ascensão da elite dirigente do Departamento Administrativo do Serviço Público (DASP) no Estado Novo. (Dissertação de mestrado, Universidade Federal do Rio Grande do Sul). 
Carneiro, A. (2015). A Escola Superior de Administração e Negócios nos primeiros vinte anos (1941-1961): Uma análise sobre o currículo em administração (Dissertação de mestrado, EAESP-FGV).

Carneiro, A. (2019). Os preceitos gerenciais para o desenvolvimento: $A$ influência do Banco Mundial para a consolidação do gerencialismo no Brasil na década de 1990 (Tese de doutorado, EAESP-FGV).

Carrieri, A., \& Lopes, F. (2012). O avô constrói, o pai usa e o neto morre de fome: Histórias de família em uma organização. REGE, 19(1), 3-10. doi: $10.5700 /$ rege 448

Castro, E. V. de. (2018). Metafísicas canibais: Elementos para uma antropologia pós-estrutural. São Paulo, SP: Cosac Naify.

Chaym, C. (2017). ANTi-History: O organizar de práticas científicas em biotecnologia (Dissertação de mestrado, Universidade Estadual do Ceará, Fundação Cearense de Apoio ao Desenvolvimento Científico e Tecnológico).

Clark, P., \& Rowlinson, M. (2004). The treatment of history in organisation studies: Towards an ‘historic turn'? Business History, 46(3), 331-352. doi: 10.1080/0007679042000219175

Coelho, F. (2006). Educação superior, formação de administradores e setor público: Um estudo sobre o ensino de administração pública - em nível de graduação - no Brasil (Tese de doutorado, Escola de Administração de São Paulo, Fundação Getulio Vargas).

Cook, B. (2003). The denial of slavery in management studies. Journal of Management Studies, 40(8), 1895-1918. doi: 10.1046/j.1467$6486.2003 .00405 . x$

Cooke, B., \& Alcadipani, R. (2015). Toward a global history of management education: The case of the Ford Foundation and the São Paulo School of Business Administration, Brazil. Academy of Management Learning \& Education, 14(4), 482-499. doi: 10.5465/ amle.2013.0147

Coraiola, D. (2012). Importância dos arquivos empresariais para a pesquisa histórica em administração no Brasil. Cadernos EBAPE.BR, 10(2), 254-269. doi: 10.1590/S1679-39512012000200002

Coraiola, D., \& Derry, R. (in press). Remembering to forget: The historic irresponsibility of U.S. Big Tobacco. Journal of Business Ethics. doi: 10.1007/s10551-019-04323-4

Correia, G. (2020). Uma grande solidão em meio à multidão: Histórias e memórias da arbitragem de futebol em Minas Gerais (Dissertação de mestrado, Cepead/Cad/Face/Universidade Federal de Minas Gerais).

Costa, A., Barros, D., \& Martins, P. (2010). Perspectiva histórica em administração: Novos objetos, novos problemas, novas abordagens. RAE-Revista de Administração de Empresas, 50(3), 288-299. doi: 10.1590/S0034-75902010000300005

Costa, A., \& Silva, M. (2017). Novas fontes, novas versões: Contribuições do acervo da Comissão Nacional da Verdade. Revista de Administração Contemporânea, 21(2), 163-183. doi: 10.1590/19827849 rac2017150101

Costa, A., \& Silva, M. (2018). Empresas, violação dos direitos humanos e ditadura civil militar brasileira: A perspectiva da Comissão Nacional da Verdade. Organizações \& Sociedade, 25(84), 15-29. doi: 10.1590/1984-9240841

Curado, I. (2001). O desenvolvimento dos saberes administrativos em São Paulo: Uma análise histórica (Tese de doutorado, EAESP/FGV).

Decker, S. (2013). The silence of the archives: Business history, postcolonialism and archival ethnography. Management \& Organizational History, 8(2), 155-173. doi: 10.1080/17449359.2012.761491
Durepos, G., \& Mills, A. (2012). Actor-network theory, ANTi-history and critical organizational historiography. Organization, 19(6), 703-721. doi: $10.1177 / 1350508411420196$

Durepos, G., Shaffner, E. C., \& Taylor, S. (2019). Developing critical organizational history: Context, practice and implications. Advance online publication. Organization. doi: 10.1177/1350508419883381

Dussel, E., \& E. Ibarra-Colado. (2006). Globalization, organization and the ethics of liberation. Organization, 13(4), 489-508. doi: $10.1177 / 1350508406065852$

Fischer, T. (1984). O ensino da administração pública no Brasil, os ideais do desenvolvimento e as dimensões da racionalidade (Tese de doutorado, USP).

Foster, W., Coraiola, D., Suddaby, R., Kroezen, J., \& Chandler, D. (2017). The strategic use of historical narratives: A theorethical framework. Journal of Business History, 59(8), 1176-1200. doi: 10.1080/00076791.2016.1224234

Fucs, A. (2019). O papel da memória (re)construção de identidade organizacional: O caso da escola Edem (Dissertação de mestrado, Pontifícia Universidade Católica do Rio de Janeiro).

Holan, P., \& Phillips, N. (2004) Organizational forgetting as strategy. Strategic Organization, 2(4), 423-433. doi: $10.1177 / 1476127004047620$

Joaquim, N. (2014). [Sub]Vidas secas nos retratos dos agricultores do Projeto Bebedouro no Semiárido de Petrolina (PE) (Tese de doutorado, Cepead/Cad/Face/Universidade Federal de Minas Gerais).

Lima, G. (2009). Memórias da gestão: O percurso da identidade administrativa de tropeiros em Minas Gerais (Dissertação de mestrado, Cepead/Cad/Face/Universidade Federal de Minas Gerais).

Lipartito, K. (2014). Historical sources and data. In M. Bucheli, \& D. Wadhwani (Orgs.), Organizations in time: History, theory, methods (pp. 284-304). Oxford, UK: Oxford University Press.

Lopes, L. (2019). O organizar das práticas de espaço à luz da perspectiva histórica: A arquitetura de ferro na cidade de Fortaleza (Tese de doutorado, Universidade Estadual do Ceará).

Lopes, F. T., \& Carrieri, A. (2010). Fotografias de família pela ótica das sucessoras: Um estudo sobre uma organização familiar. Revista de Administração Contemporânea, 14(3), 478-494. doi: 10.1590/S141565552010000300006

Maclean, M., Harvey, C., Clegg, \& Stewart R. (2016). Conceptualizing historical organization studies. Academy of Management Review, 41(4), 609-632. doi: 10.5465/amr.2014.0133

Marini, R. (2012). Subdesenvolvimento e revolução. Florianópolis, SC: Insular.

Martins, P., Gurgel, C., Lima, D., Darbilly, L., Justen, A., Santos, C. (2013). Referência aos clássicos interpretativos do Brasil no pensamento acadêmico contemporâneo sobre administração pública. In C. Gurgel, \& P. E. M. Martins (Orgs.), Estado, organização e pensamento social brasileiro, (pp. 13-40). Rio de Janeiro, RJ: Editora UFF.

Mignolo, W., \& Tlostanova, M. (2006). Theorizing from the borders: Shifting to geo-and body-politics of knowledge. European Journal of Social Theory, 9(2), 205-221. doi: 10.1177/1368431006063333

Mir, R., \& Mir, A. (2012). The colony writes back: As an early champion of non-western organizational theory. Organization, 20(1), 91-101. doi: $10.1177 / 1350508412461003$

Morgado, U. (2016). Identidade na organização-cidade de Curitiba: Estudo histórico da primeira gestão de Jaime Lerner (Dissertação de mestrado, Universidade Positivo). 
Pio, E., Júnior. (2018). A Sudene de Celso Furtado na reforma do Estado (1959-1964) (Dissertação de Mestrado, Unigranrio).

Prost, A. (2012). Doze lições sobre a história. São Paulo: Autêntica.

Quelha-de-Sá, R. (2018). Em busca de transparência: Uma análise das movimentações sócio-políticas dos múltiplos atores envolvidos no processo de constituição do Memorial da Resistência de São Paulo (MRSP) à luz da abordagem ANTi-History (Dissertação de mestrado, Pontifícia Universidade Católica do Rio de Janeiro).

Quelha-de-Sá, R., \& Costa, A. (2019). In search of transparency: ANTiHistory, memorials and resistance. Journal of Management History, 25(4), 493-515. doi: 10.1108/JMH-02-2018-0012

Ramos, A. G. (1958). A redução sociológica: Introdução ao estudo da razão sociológica. Rio de Janeiro, RJ: ISEB.

Rowlinson, M., Booth, C., Delahaye, A., \& Procter, S. (2010). Social remembering and organizational memory. Organization Studies, 31(1), 69-87. doi: 10.1177/0170840609347056

Rowlinson, M., Hassard, J., \& Decker, S. (2014). Research strategies for organizational history: A dialogue between historical theory and organization theory. Academy of Management Review, 39(3), 250274. doi: 10.5465/amr.2012.0203

Santos, C. (2019). Imprensa, discurso e ideologia: O jornal Folha de São Paulo e o Golpe de Estado de 1964 (Dissertação de mestrado, Pontifícia Universidade Católica do Rio de Janeiro).

Schrempf-Stirling, J., Palazzo, G., \& Phillips, R. (2016). Historic corporate social responsibility. Academy of Management Review, 41(4), $700-$ 719. doi: 10.5465/amr.2014.0137

Silva, E. (2019). Entre vivências e lembranças de um quilombo urbano: História, memória e discurso (Dissertação de mestrado, Universidade Federal de Minas Gerais).

Silva, M. (2017). História organizacional da ENAP: Uma análise dos papéis desempenhados e das competências organizacionais desenvolvidas (Tese de doutorado, Universidade Federal da Bahia).

Silva, M.A.C. (2018). As práticas de normalização da violência operacionalizadas pela Volkswagen do Brasil na ditadura militar brasileira (1964-1985) (Tese de doutorado, Pontifícia Universidade Católica do Rio de Janeiro).

Silva, M. A. F. (2018). A carne mais barata do mercado é a carne negra: Um estudo com histórias de vida de trabalhadores industriais negros (Dissertação de mestrado, Universidade Federal de Minas Gerais).

Souza, R. (2016). Interculturalidade em uma organização de origem em países distintos: Uma história da Inaceres (Tese de doutorado, Universidade Federal da Bahia).

Stokes, P., \& Gabriel, Y. (2010). Engaging with genocide: The challenge for organization and management studies. Organization, 17(4), 461480. doi: $10.1177 / 1350508409353198$

Suddaby, R., Foster, W. M., \& Trank, C. Q. (2016). Re-Membering: Rhetorical history as identity work. In M. G. Pratt, M. Schultz, B. E. Ashforth, \& D. Ravasi (Eds.), The Oxford handbook of organizational identity. Oxford: Oxford University Press.
Taunay, C. (2001). Manual do agricultor brasileiro. São Paulo, SP: Companhia das Letras.

Tonelli, M. J. (2017). The foundation of the academic field in business and administration in Brazil: The case of RAUSP. RAUSP-Revista de Administração, 52(4), 359-362. doi: 10.1016/j.rausp.2017.08.001

Tonelli, M. J. (2018). Revistas científicas em administração: O papel histórico da Revista de Administração de Empresas (RAE) na construção do campo acadêmico em administração no Brasil. Cadernos EBAPE.BR, 16(spe), 509-5015. doi: 10.1590/1679395173941

Valle, M. M., Bertero, C., \& Alcadipani, R. (2013). Caminhos diferentes da americanização na educação em administração no Brasil: A EAESP/FGV e a FEA/USP. Administração: Ensino e Pesquisa (RAEP), 14(4), 837-872. doi: 10.13058/raep.2013.v14n4.49

Vizeu, F. (2008). Management no Brasil em perspectiva histórica: o projeto do IDORT nas décadas de 1930 e 1940 (Tese de doutorado, $\mathrm{EAESP} / \mathrm{FGV}$ ).

Vizeu, F. (2010). Potencialidades da análise histórica nos estudos organizacionais brasileiros. RAE-Revista de Administração de Empresas, 50(1), 37-47. doi: 10.1590/So034-75902010000100004

Vizeu, F. (2018). IDORT e difusão do management no Brasil na década de 1930. RAE-Revista de Administração de Empresas, 58(2), 163-173. doi: 10.1590/s0034-759020180205

Wadhwani, R. D., Suddaby, R., Mordhorst, M., \& Popp, A. (2018). History as organizing: Uses of the past in organization studies. Organization Studies, 39(12), 1663-1683. doi: 10.1177/0170840618814867

Waiandt, C. (2009). O ensino dos estudos organizacionais nos cursos de pós-graduação stricto sensu em administração (Tese de doutorado, Universidade Federal da Bahia).

Walsh, J., \& Ungson, G. (1991). Organizational memory. Academy of Management Review, 16(1), 57-91. doi: 10.2307/258607

Wanderley, S. (2015). Desenvolvimentismo, descolonidade e a geohistória da administração no Brasil: A atuação da CEPAL e do ISEB como instituições de ensino e pesquisa em nível de pós-graduação (Tese de doutorado, EBAPE/FGV).

Wanderley, S. (2016). ISEB, uma escola de governo: Desenvolvimentismo e a formação de técnicos e dirigentes. Revista de Administração Pública, 50(6), 913-936. doi: 10.1590/0034-7612150061

Wanderley, S., \& Barros, A. (2019). Decoloniality, geopolitics of knowledge and historic turn: Towards a Latin American agenda. Management \& Organizational History, 14(1), 79-97. doi: $10.1080 / 17449359.2018 .1431551$

Wanderley, S., \& Barros, A. (2020). The Alliance for Progress, modernization theory, and the history of management education: The case of CEPAL in Brazil. Management Learning, 51(1) 55-72. doi: $10.1177 / 1350507619869013$

Yates, J. (2014). Understanding historical methods in organization studies. In M. Bucheli, \& D. R. Wadhwani (Orgs.), Organizations in time: History, theory, methods (pp. 265-283). Oxford: Oxford University Press.

\section{CONTRIBUIÇÃO DOS AUTORES}

O trabalho foi pensado, refletido e escrito de forma conjunta. A autora e o autor desenvolveram juntos todo o trabalho desde o levantamento de informações, a conceituação e abordagem teórica-metodológica, a revisão teórica (levantamento de literatura), até a redação e revisão final do texto. 